\title{
Using Science, Technology, Society, and Environment (STSE) Approach to Improve the Scientific Literacy of Grade 11 Students in Plant Growth and Development
}

\author{
Kultida Chanapimuk $^{1 *}$, Sureeporn Sawangmek ${ }^{1}$, Pranee Nangngam² \\ ${ }^{1}$ Faculty of Education, Naresuan University, Tha Pho, Meueang Phitsanulok District, Phitsanulok 65000, Thailand \\ ${ }^{2}$ Faculty of Science, Naresuan University, Tha Pho, Meueang Phitsanulok District, Phitsanulok 65000, Thailand \\ *Corresponding Author. kultidach59@email.nu.ac.th
}

\begin{abstract}
The environmental issues surrounding agrochemical products facing people today include serious health and ecological problems. Scientific literacy is necessary for students to understand scientific knowledge and get ready for the future world. Therefore, this action research aims to promote scientific literacy, in the area of plant growth by using the Science, Technology, Society and Environment (STSE) approach that consists of 4 steps: 1) motivation; 2) exploration; 3) brainstorming; and 4) decision making. The participants are 35 special program students in grade 11. The PISA-like test and worksheets were used to collect data. Content analysis and triangulation were used to indicate the development of scientific literacy. The findings show that the students have better scientific literacy and higher competencies in explaining phenomena scientifically, evaluating and designing scientific inquiry and interpreting data and evidence scientifically. This study suggests that student collaboration is essential to improve the scientific literacy of students.
\end{abstract}

Keywords Science, Technology, Society and Environment Approach, Scientific Literacy, Plant Growth, and Development

\section{INTRODUCTION}

In the twenty-first century, science and technology progressed greatly. While uses of scientific knowledge have been of great benefit to humankind, it also led to negative effects on society and the environment. For the example, harmful raw materials, which used in food and drink production process, have caused many people unhealthy. Some of the environmental issues cause of chemical products using. Accordingly, many countries prepare their citizens by including scientific knowledge in the school curriculum and enabling people to adapt to the future world (Organization for Economic Co-operation and Development; OECD, 2016a). Therefore, young people should be able to use science to identify and solve problems in the real world because scientific knowledge is the base of development in the modern nation. Scientific literacy is one of the necessary components of education that drives society (Ogunkola, 2013). Not only teachers teach the student to use scientific knowledge to explain phenomena, but also should guide students to apply related knowledge and draw appropriate conclusions based on scientific evidence. The opportunity to use science in everyday life comes from appreciating scientific processes (Klainin,
Datesri, \& Pramodnee, 2008). Moreover, the environmental issues in Thailand include the use of chemicals caused by development technology which requires people to understand technology and its possibility to impact on the environment. This is the reason why students should be prepared to develop their scientific literacy.

However, the result from the program for international education systems assessment (PISA) in 2015 indicated that Thai students' scored were 421 points in science literacy which far lower than the average of OECD countries (OECD, 2016b). It shows that Thai students lack scientific literacy competencies. Such competencies include the explanation of phenomena, the evaluation, and design of scientific inquiry and the interpretation of data. They can use their basic scientific knowledge to give some explanation of familiar situations such as they may encounter in the classroom, but they cannot integrate their knowledge to real-world situations (The Institute for the

Received: 16 July 2018

Revised: 23 September 2018

Published: 3 December 2018 
Promotion of Teaching Science and Technology, 2017). This result is similar to the observations of the researcher's monitoring in a high school biology class, where the students could not draw a diagram of a plant structure after observing it under a microscope. Students are unable to draw in the proportion of a diagram from what they observed. These observations show that they have low scientific inquiry skill and rarely able to interpret the information from observation. Many students could explain the nature of the plant tissue, but they could not explain with evidence why monocotyledonous plants have differences in structure. This result indicates that students lack the ability to provide evidence to support their explanations. From these observations, it is apparent that the students in this study need to improve their scientific literacy.

Science, technology, society, and environment (STSE) approach focuses on using the result of science and technology that affects society and the environment in the science lesson. It can be used for improving the students' ability to apply their scientific knowledge in order to comprehend the relationship between what they learn in the classroom and what occurs in their daily life and also make meaningful scientific learning (Pedretti et al., 2008; Pedretti \& Nazir, 2011). In addition, students have the opportunity to practice asking scientifically valid questions, designing experiments, exploring, analyzing and interpreting data to find solutions to solve the problem. Students also need to recognize the social and physical environment through the socio-scientific context (Pedretti \& Nazir, 2011). In another research, STSE process was used to promote students' scientific literacy in ecosystem topics (Gresch, Hasselhorn, \& Bogeholz, 2015).

In this study which used the STSE approach modified from Lau (2013) could improve students' ability to develop their scientific literacy. This approach consists of 4 steps; 1) motivation, encourage students to be aware of important environmental issues and contexts. In the context of this study, plant growth was examined in the context of chemical pollutants; 2) exploration, students were encouraged to examine this issue and to find possible solutions; 3) brainstorming, brainstorming was used to collect information and ideas, then interpret the information; 4) decision making, students had to decide the best solution of the class from presentation and discussion.

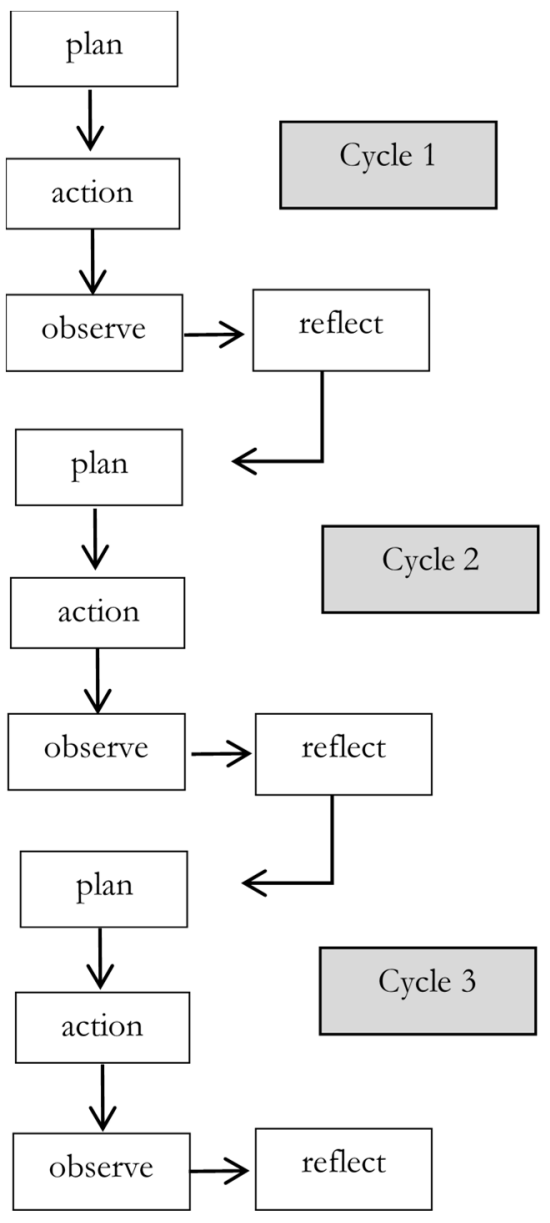

Topic 1: The effect of using chemical coating in corn seed

Action with STSE approach: motivation, exploration, brainstorming and decision making

Topic 2: The effect of using large amounts of insecticide and GMOs plants

Action with STSE approach: motivation, exploration, brainstorming and decision making

Topic 3: The effect of chemical plant growth hormones on banana planting

Action with STSE approach: motivation, exploration, brainstorming and decision making

Figure 1 A research methodology 
Specifically, the research question in this study was "How the impact of the Science, Technology, Society, and Environment approach affect to improve the scientific literacy of grade 11 students in the topic of plant growth and development"

\section{METHOD}

\subsection{Methodology}

This research design is based on the concepts of action research. The developmental model used in this study refers to Kemmis \& McTaggart (2014). There are four main phases in a cycle of action research including PlanAct-Observe-Reflect (PAOR). This study includes three cycles which have different topics that each cycle lasted 4 hours. The research methodology as shown in Figure 1.

\subsection{Science, Technology, Society and Environment approach}

The Science, Technology, Society, and Environment approach was adopted in this study from Lau (2013). This process consists of four steps: motivation, exploration, brainstorming, decision making. The detail of STSE approach in this study was described as following.

First, the step is motivation, the teacher presented an environmental issue and context to the class. Then, each group of students was asked to determine what scientific questions they would ask in the same environmental issues which different environmental issues in each learning cycle following by 1) The effect of using chemical coating in corn seed; 2) The effect of using large amounts of insecticide and GMOs plants; 3) The effect of chemical plant growth hormones on banana planting. The second step is exploration, the participants work in a collaborative group in order to design a method for exploration, collecting information, searching for evidence and analyzing data to answer the questions that they asked in the previous step. The third step is brainstorming, the members of each group shared possible solutions and choose the best way to solve the problem according to the data collected and interpreted. Then, they prepared to present their solution. The presentation could be a poster presentation, diagram, brochures, PowerPoint, etc. The final step of the approach is decision making. All the groups present a solution and discuss the pros and cons of the solution. After each group has finished their presentation, the students will decide which is the best solution overall.

\subsection{Participants}

The research explored in this study involved Grade 11 students of Phitsanulok province in northern Thailand. The samples comprised 35 students ( 31 boys and 4 girls) in a special program in the Sciences and Mathematics.

\subsection{Data Collection}

The instruments used for data collecting were the PISAlike test and student worksheets. The PISA-like test has 12 items consisting of multiple choices, complex multiple choices and open-ended questions in order to assess scientific literacy before and after the learning activities with STSE. The quality of the test to its validity by using Index of Consistency (IOC) from three experts. The experts consisted of a professor from a faculty of agriculture natural resources and environment, a professor from a faculty of science education and a biology specialist teacher from the school where collected the data. The Index of Consistency of 12 items in the test was between 0.67 - 1. It demonstrated that the test consistent with content. Student worksheets were used to collect information about student scientific literacy during learning activities in each cycle total of three cycles. By dividing students into eight group, each group has to collaborate to complete student worksheet. Then, submit to a researcher at the end of each cycle.

\subsection{Data analysis}

The data was collected from two instruments: 1) assessing the PISA-like tests by using criteria similar to the PISA 2015 framework (OECD, 2016a); 2) assessing the

Table 1 Scientific competencies description

\begin{tabular}{ll}
\hline Scientific competencies & Sub-competencies \\
\hline Explaining phenomena scientifically $(6$ & - Indicate, use and make some representations for explanation \\
points) & - describe scientific knowledge in terms of its potential implications for society \\
Evaluating and designing scientific & - Ask scientific questions \\
inquiry & - Distinguish questions to be explored \\
$(15$ points) & - Offer a way of exploration \\
& - Estimate the way of exploration \\
& - Describe and estimate how scientists ensure the credibility of data \\
Interpreting data and evidence & - Convert data to a different representation (e.g. chart, diagram, etc.) \\
scientifically & - Analyze, interpret and draw conclusions from the gathered data \\
$(15$ points) & - Identify the supposition, evidence, and reasoning based on scientific knowledge \\
& - Distinguish between scientific evidence, justification, and other considerations \\
& - Estimate scientific justification and evidence from different sources \\
\hline
\end{tabular}

Note. Adapted from "PISA 2015 Assessment and Analytical Framework: Science, Reading, Mathematics, Financial Literacy, and Collaborative Problem Solving," by OECD, 2016, p. 24-25. 
Table 2 The percentage of scores in each competency and scientific literacy level of students

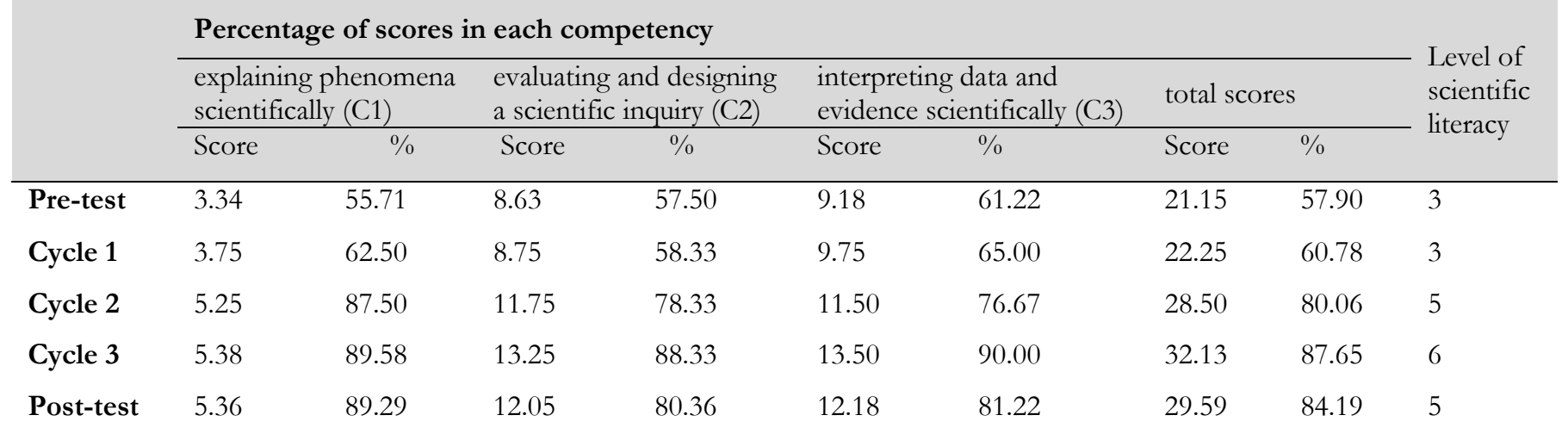

student worksheets by given mark scientific competencies and sub-competencies that students demonstrated during the cycles. The scientific competencies are component of scientific literacy to indicate that students are able to handle with science-related issues (see Table 1). The rubric score comprises as follow; 0- exhibit no competencies; 1 - exhibit low competencies; 2- exhibit more good competencies; 3 exhibit good competencies with content analysis. Then, the results of both instruments were evaluated with basic statistics include of Percentage and Mean, then categorized them to scientific literacy levels developed from PISA 2015 framework into 7 levels as following; level $6(87.5-100 \%)$; level 5 (75-87.4\%); level 4 (62-74.5\%); level 3 (50.5-63\%); level 2 (37.5-50\%); level 1b (25.5-37\%); level 1a (12.5-26\%), (OECD, 2016). Next, scientific competencies were compared between three phases including before, during and after study with the STSE approach. Finally, the result's trustworthiness was established by using method triangulation that compares the results from the PISA-like test and student worksheets.

\section{RESULT AND DISCUSSION}

The analysis and discussion of the results will be presented as percentages of the scientific competencies and the level of scientific literacy from the PISA-like test and the student worksheets. The results are clarified in Table 2 .

An increasing of students' competencies before and after learning was shown in table 2 which were measured by the PISA-like test. In the pre-test, students indicated their highest level of development in C3, at $61.22 \%$. After the students studied through STSE approach, the percentage of total scores at the post-test was higher than in the pre-test, at $84.19 \%$ and $57.90 \%$ respectively. The best-developed competency was $\mathrm{C} 1$ at $89.29 \%$ in post-test. Consistent with the result, teaching with STSE had been able to improve the competencies of scientific literacy after learning.

An improvement of students' competencies was demonstrated in Table 2 which were assessed by student worksheets during the learning activity. From this table, the percentage of student competency scores continually raised from cycle 1 to 3 , at $60.78 \%$ and $87.65 \%$ respectively.

DOI: $10.17509 /$ jsl.v2i1.11997
Especially, C3 was significantly increased to $90 \%$ in cycle 3 , while $\mathrm{C} 1$ slightly increased to $89.58 \%$. It can be seen from Table 2 that the students increased their competencies in scientific literacy when they learned with STSE for three cycles. From these results evaluating by PISA-like test and student worksheets indicated that student improved their scientific competencies of scientific literacy though STSE approach. The results of this competencies as descript below.

In an aspect of $\mathrm{C} 1$, the students' competencies were evaluated by students given explanations in class. In cycle 1 , the students explained the chemical using in corn seed's solution. Their findings can be presented with a simple solution for explaining how a new chemical that they use was useful. As group 1 commented in their report: "Using polyetbylene glycol 600 is good for the environment because it is low toxic, can protect the seed and low absorb into a buman." (Group 1, Cycle 1). This comment has shown that student created a poor explanation without scientific knowledge. In cycle 2 , students' explaining competency significantly improves from cycle 1 as shown in Table 2 . The students were able to draw a representation from the presented problem and explaining to the others in class after they had the additional time for brainstorming with members of their group. Their illustrations and findings can be presented with possible benefits of their solution to society as a whole, which their evaluation of the advantages of the GMOs plant issue according to the potential solutions. Group 1 commented in their report: "The benefits of using physostigmine instead of glyphosate products are that they are watersoluble chemicals that are safe for the environment and plants. The weakness of this solution is that it can lead to acidic soil. This problem can be solved by adding lime ( $\mathrm{CaO}$ ) to the soil." (Group 1, Cycle $2)$. In cycle 3 , the students had a good progression of explaining competency. As group 7 reported in a worksheet: "Using Effective Microorganisms makes soil degradation and soil has more oxygens. It activates microbial resistant for soil and plant will be growth by nitrogen fixation. Providing the chances for students to present their finding and brainstorming with their member group though STSE approach would promote the ability to explain the phenomena. According to Ladachart \& Yuenyoung (2016) 
which stated that building the opportunity for students to discuss their explanations was developed the ability to explain phenomena competently. Furthermore, Hidayanti, Pochintaniawati, \& Agustin (2018) also proved that brainstorming can attribute the student to give an accurate explanation and estimation possible way to solve the problem.

In an aspect of C2, it can be seen in the students' work that they could improve their competency during the exploratory process in which they began to organize and evaluate possible ways to solve the presented problem. They would need to consider the problem and appropriate questions that would need to be answered to solve the given problem. From there, they can decide what exploratory steps to take. In cycle 1 , most of the students had poorly designed their own literature review before finding the solution. The knowledge that they want to know was slightly comprehensive with the topic. As group 6 commented in a worksheet: "We start to review about biochemical that safe for environment and buman. Then, we will find what chemical is used in the seed coat? and what is the effect when we use in the plant?" As the comment in the worksheet, it can be seen that the students' competency is developed. Consequently, teacher motivated students by using environment issue about GMOs plant and encourage them to give questions about the issue. In cycle 2 , teacher guided by questions for specific designing led to the improvement of students' competency from cycle 1 . The following quotation reveals the students designed in their worksheet:

Student's report in cycle 1 (Group 8)

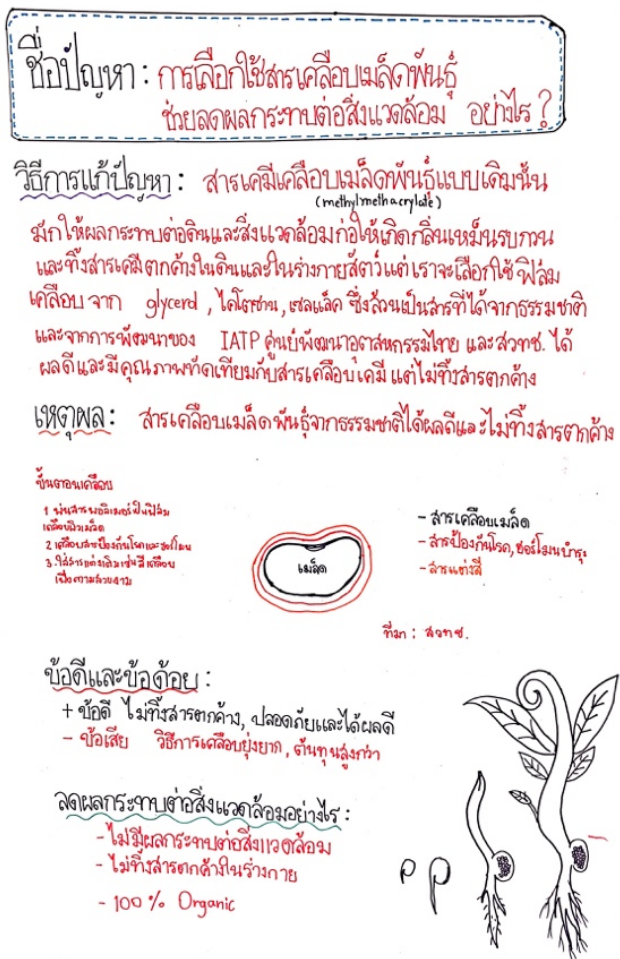

"We think the knowledge that should review to answer our question is what chemical that non-toxic. Organophosphate is safe, so we should search what does it work? and how it uses in the plant?" In cycle 3 , the students had good development of evaluating and designing competency. They could search and review appropriate literature on the subject. For example, they could collect data by reviewing the literature about plant growth and some experiments from existing research papers. In the comment written of group 8' s worksheet: "The knowledge that is necessary to exploration included 1) ethylene was planted hormone that associated with fruit senescence, 2) fruit ripening was the process of changing methionine to ethylene that could lead to a sweet flavor in ripe fruit, 3) acetaldehyde could inbibit the synthesis of ethylene by bonding with the protein function group that could delay the fruit ripening..." (Group 8, Cycle 3). Training the students through the exploration step leads the students encouraging scientific literacy. In line with Ladachart \& Yuenyoung (2016) which stated that students who are trained in the scientific procedure (i.e. Identify question, scientific inquiry, appraise ways of investigation) tended to draw on their own understanding and exploratory methods. Moreover, Eliyawati, Sunarya, \& Mudzakir (2017) said that the issues or situation in society that occur around the students can give a response them, attempt to find solutions and pay attention to explanation carefully.

In an aspect of $\mathrm{C} 3$, the students had the opportunity to transform large amounts of complicated information into a form that is easier to understand and present it in class.

\section{Student's report in cycle 3 (Group 8)}

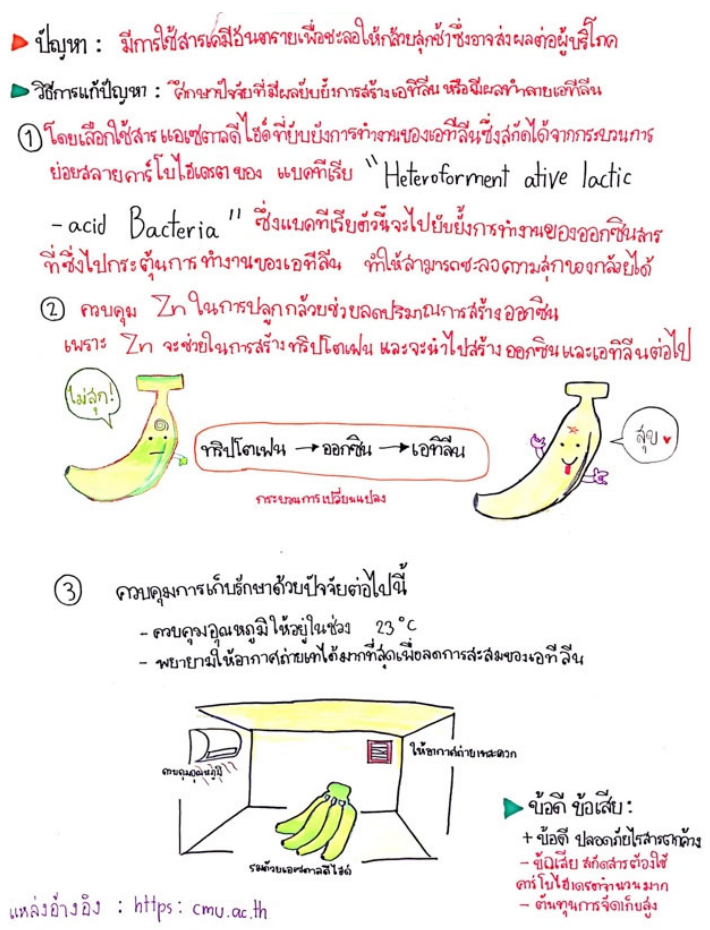

Figure 2 an example of scoring for competencies in scientific literacy of students in cycle 1 and 3 
They presented their findings based on the scientific evidence, discussed other findings and considered choosing the best alternative solution of the class. Students' work is presented in Figure 2. Practicing the students to transform and discuss based on the scientific evidence leads the students developing the competency of interpreting data and evidence scientifically. According to Ladachart \& Yuenyoung (2016) who state that: the teacher should train students to modify the data by turning it into a graph or other form of representation. Moreover, Gresch, Hasselhorn, \& Bogeholz (2015) indicated that the decision-making process could be enhanced or justified because students had the chance to identify the scientific evidence and use it to distinguish the claims of others in the class and consider choosing the best solution through the process of argumentation.

Figure 2 shows cycle 1 and 3 from Group 8's worksheets. The initial and final representations of Group 8 included information on the explored problem. The students examine the positive and negative implications in the situation for the environment and society. Additionally, Students could associate the following solutions to solve the problem and how this solution may help the environment and society. Moreover, they can create a simple model to explain their solution based on group findings through the process of STSE. In cycle 1, students created a simple representation by using investigated documents to be a short word. They did not represent the data as a diagram, etc. Rather, the competency of the interpretation of data and evidence significantly improved from cycle 1 . For the evidence as shown in Figure 2, the students generated an appropriate representation that was shown by their own understanding and linked scientific knowledge to explain how the solution worked as diagram about changing of substances in banana when it ripens.

For overall results, students' scientific literacy improved during the learning cycle because they had opportunities to draw their scientific exploration, analyze investigated data and construct their scientific explanation through three cycles of STSE approach. The researcher would conclude that learning though STSE could promote scientific literacy of students, according to the increase of scientific literacy during STSE activity in three cycles and the enhancing after learning score in post-test.

Similar to the level of scientific literacy developing in each cycle, the level of scientific literacy increased progressively from level 3 in cycle 1 to level 6 in cycle 3 . In the same way, the scientific literacy level of students in post-test (level 5) was higher than in pre-test (level 3). However, the percentage of total scores in cycle 3 was higher than post-test, at $87.65 \%$ and $84.19 \%$ respectively. This is because the students collaborated with others in their group through the process of exploration and brainstorming. Thus, the process of group work included chances to assist students in exchanging complicated information from different sources, which promoted group work where friends verified the information. The researcher suggests that group collaboration will promote the students' scientific literacy. It is in line with a previous study of Rosario (2009) which stated that: "...focus-group discussion will lead students to prefer the freedom given to them to choose their activities rather than simply accept prepared activities provided by the teacher...".

Based on a result of scientific literacy developing during the study from students' worksheets and a result of the pretest and post-test from the PISA-like test, it shows that the scientific literacy level of both was increased. This indicates that student scientific literacy progressed because of the process of STSE though environmental topics related to society for relevant science learning. It is in line with Yoruk (2010) who stated that: "The STSE teaching approach promotes students in recognizing their own skill and enables them to learn more meaningfully than by traditional teaching".

\section{CONCLUSION}

Based on the results and discussion the STSE approach is supportive of the conclusion that STSE is able to improve the scientific literacy of students which applied their knowledge in the topic of plant growth and development. They understand the effect of the issues and why they might solve these issues and find solutions through the process of STSE. Most of the students could design an experiment and find a solution to environmental issues. They are also able to consider the effect of the solution on the environment and society as a whole. These results also suggest that student collaboration is essential to fully develop student scientific literacy.

\section{ACKNOWLEDGMENT}

The researcher is grateful for the support from the Institute for the Promotion of Teaching Science and Technology that supported the scholarship and the Faculty of Education, Naresuan University, Thailand. The researcher appreciates the interest and participation of my advisor, the students and my boyfriend who made this work possible.

\section{REFERENCES}

Eliyawati, Sunarya, Y., \& Mudzakir, A. (2017). Solar cell as learning multimedia to improve students' scientific literacy on science and nanotechnology. Journal of Science Learning, 1(1),36-43.

Gresch, H., Hasselhorn, M., and Bögeholz, S. (2015). Enhancing Decision-Making in STSE Education by Inducing Reflection and Self-Regulated Learning. Science Education, 47(1), 95-118.

Hidayanti, W., I., Rochintaniawati, D., \& Agustin, R. R. (2018). The Effect of Brainstorming on students' creative thinking skill in learning nutrition. Journal of Science Learning, 1(2),44-48.

Kemmis, S., McTaggart, R., \& Nixon, R. (2014). The action research planner: doing critical participatory action research. singapore. 
Klainin, S., Datesri, P., and Pramodnee, A. (2008). Knowledge and scientific competency for the future world. Thailand: The Institute for the Promotion of Teaching Science and Technology)

Ladachart, L. and Yuenyoung, C. (2016). What Thai Science Teachers Sould Learn From The Programme for International Student Assessment. Parichart Journal, Thailand: Thanksin University, 28(2) 108-37

Lau, K. (2013). Impacts of a STSE high school biology course on the scientific literacy of Hong Kong students. Asia-Pacific Forum on Science Learning and Teaching, 14(1), 1-25.

Ogunkola, B. (2013) Scientific Literacy: Conceptual Overview, Importance and Strategies for Improvement. Journal of Educational and Social Research, 3(1), 265-274.

Organisation for Economic Co-operation and Development (OECD). (2016a). PISA 2015 Assessment and Analytical Framework: Science, Reading, Mathematic, Financial Literacy and Collaborative Problem Solving, revised edition. Paris: OECD publishing.
Organisation for Economic Co-operation and Development (OECD). (2016b). PIS A 2015 PIS A Results in Focus. Retrieved March 5, 2017, from https://www.oecd.org/pisa/pisa-2015-results-in-focus.pdf.

Pedretti, E. and Nazir, J. (2011). Currents in STSE Education: Mapping a Complex Field, 40 Years On. Science Education, 95(601), 601-626.

Pedretti, E. G., Bencze, L., and Hewitt, J. (2008). Promoting Issuesbased STSE Perspectives in Science Teacher Education: Problems of Identity and Ideology. Science Education, 17(1):941-960.

Rosario, B. I. D. (2009). Science, Technology, Society and Environment (STSE) Approach in Environmental Science for Conscience Students in a Local Culture. CHED Accredited Research Journal, 6(1), 269-283.

The Institute for the Promotion of Teaching Science and Technology. (2017). The basic information summary of PIS A 2015. Thailand: The Institute for the Promotion of Teaching Science and Technology

Yoruk, N., Morgil, I., Secken, N. (2009). The effects of science, technology, society and environment (STSE) education on students' career planning. US-China Education Review, 6(8), 68-74. 